\title{
DEĞIŞEN YÜZÜYLE DOĞRUDAN PAZARLAMADA TELEVIZYON REKLAMLARI
}

Dr. Ayla TOPUZ SAVAŞ 


\section{(C) Copyright 2020}

Bu kitabın, basım, yayın ve satış haklar Akademisyen Kitabevi A.Ş.'ne aittir. Anılan kuruluşun izni alınmadan kitabın tümü ya da Bölümleri mekanik, elektronik, fotokopi, manyetik kağıt ve/veya başka yöntemlerle çoğaltılamaz, basılamaz, dağıtılamaz. Tablo, şekil ve grafikler izin alınmadan, ticari amaçh kullanılamaz. Bu kitap T.C. Kültür Bakanlığ bandrolü ile satılmaktadır.

\section{ISBN}

978-625-7707-79-4

\section{Kitap Adı}

Değişen Yüzüyle Doğrudan Pazarlamada

Televizyon Reklamları

\section{Yazar}

Ayla TOPUZ SAVAŞ

ORCID iD: 0000-0003-3604-5561

\section{Yayın Koordinatörü}

Yasin Dilmen

\section{Sayfa ve Kapak Tasarımı}

Akademisyen Dizgi Ünitesi

Yayıncı Sertifika No

47518

\section{Baskı ve Cilt}

Vadi Matbaacilık

\section{Bisac Code}

BUS043010

\section{DOI}

10.37609/akya.831

\section{GENEL DAĞITIM Akademisyen Kitabevi A.Ş.}

Halk Sokak 5 / A

Yenişehir / Ankara

Tel: o312 4311633

siparis@akademisyen.com 


\section{ÖNSÖZ}

Her geçen yıl talebin arttığı internet aracılığıyla satışın/e-ticaretin temelleri doğrudan pazarlamaya dayanır. Doğrudan pazarlama (direct marketing) uzun yıllar farklı reklam araçlarıyla uygulanmış, temel kuralları olan stratejik bir kavramdır.

İlk bölümde, doğrudan pazarlama ile yeni tüketici kavramı, tüketicinin değişen yaşam tarzı, ürün zayiatı (shrinkage), niş pazar ve kitlesel bireyselleştirme ilişkilendirilmiştir.

Çalışmanın ana konusunu ise doğrudan pazarlama televizyon reklamları oluşturmaktadır. Doğrudan pazarlama araçlarından olan TV reklamları, yaratıcılıktan uzak yayınlar olarak görülmüş, akademik olarak da ilgi gösterilmemiştir. Ancak son dönemde bu tür reklamlar yaratıcılığın, ünlülerin ve reklam çekiciliklerinin kullanıldığı yüksek bütçeli TV reklamları haline gelmiştir. Bu reklamlar iki farklı forma sahiptir: Infomercial uygulamalar ve doğrudan tepki televizyon reklamları (direct response TV).

Infomercial uygulamaların tarihsel süreci açıklanmış; günümüzde e-ticaret sitelerinin reklamları olarak yayınlanan doğrudan tepki televizyon reklamları, güncel örneklerden yola çıkılarak sınıflandırılmıştır. Tüketimin arttığı özel dönemlerden biri haline gelen, Black Friday ve Efsane Kasım 2020 döneminde yayınlanan doğrudan tepki TV reklam kampanyaları değerlendirilmiştir. Bu kitapta ayrıca alanda çalışma yapmak isteyen akademisyenlere, araştırma önerileri sunulmuştur. 
Kiraz mevsimim Dervişan ve Hakan’a, 


\section{IÇiNDEKILER}

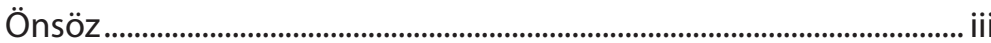

Giriş.....................................................................................................

\section{BÖLÜM \\ DOĞRUDAN PAZARLAMA}

Başlangıcından Günümüze Doğrudan Pazarlamanın

Kısa Tarihi ...................................................................................... 3

Doğrudan Pazarlama Kavramı .................................................................11

Yeni Tüketici Kavramı, Tüketicinin Değişen Yaşam Tarzı ve

Doğrudan Pazarlamanın Gelişme Nedenleri

Geleneksel Pazarlamada ve Doğrudan Pazarlamada

Ürün Zayiatı (Shrinkage)......................................................................29

Doğrudan Pazarlamada Niş Pazar ve Reklam......................................30

Doğrudan Pazarlamada Kitlesel Bireyselleştirme ve Reklam..........33

Doğrudan Pazarlamanın Zayıf Yönleri ..................................................37

Doğrudan Pazarlama Karması ................................................................38

\section{BÖLÜM \\ DOĞRUDAN PAZARLAMA TELEVIZYON REKLAMLARI}

Infomercial Uygulamalar (Ticari Amaçlı Bilgi Verici

TV Reklamlar) .49

Doğrudan Tepki Televizyon Reklamları .................................................64

Ürüne Yönelik Doğrudan Tepki TV Reklamları................................69

Markaya Yönelik Doğrudan Tepki TV Reklamları ..........................73 
vi $\mid$ İçindekiler

Aracılık Hizmeti Veren İnternet Sitesine Yönelik Doğrudan

Tepki TV Reklamları.

Alışveriş Sitelerine (E-Ticaret Sitelerine) Yönelik Doğrudan

Tepki TV Reklamları.

Mobil Uygulamalara Yönelik Doğrudan Tepki

TV Reklamları 82

Advertorial (Tanıtıcı) Doğrudan Tepki TV Reklamları ...................86

Aracı Kurumlara Yönelik Doğrudan Tepki TV Reklamları ...........88

Doğrudan Tepki Bant Reklamları....................................................90

Doğrudan Tepki TV Reklamlarında Satış Promosyonları............94

Tüketimin Arttığı Özel Dönemlerin Doğrudan Tepki TV

Reklamlarına Yansıması- Black Friday

(Kara Cuma) ve Efsane Kasım Örneği .96

Doğrudan Pazarlamanın Geleceği ve Reklamlar

Sonuç ve Öneriler.

Kaynaklar. 


\section{KAYNAKLAR}

Akın, M. (2008). Doğrudan Pazarlama. (Ed. İ. Varinli ve K. Çatı) Güncel Pazarlama Yaklaşımlarından Seçmeler. 177-201. Ankara: Detay Yayıncilık.

Altuntuğ, N. (2010). Geleneksel Tüketim Olgusunun Kırılma Noktası: Yeni Bir Tüketim Paradigmasına ve Tüketici Kimliğine Doğru. Organizasyon ve Yönetim Bilimleri Dergisi, 2 (2)

Arıkan, A. (2017). Kurumsal Tasarım ve Görsel Kimlik, Kurumsal İletişim, Eskişehir: Anadolu Üniversitesi Açıköğretim Fakültesi.

Balasubramanian, S. K. (1994). Beyond Advertising and Publicity: Hybrid Messaged and Public Policy Issues, Jounal of Advertising 23 (December) 29-46.

Barış, G. (2012). Kişilik, Benlik, Yaşam Biçimleri. Tüketici Davranışı Eskişehir: Anadolu Üniversitesi Açıköğretim Fakültesi

Baysal, A. (2006). Doğrudan Pazarlamanın Kurucusu Wunderman. MediaCat Yayınları.

Bell, G. C., Weathers, M. R., Hastings, S. O., Peterson, E. B. (2014). Investigating the Celebration of Black Friday as a Communication Ritual. Journal of Creative Communications. 9 (4). 235-251.

Bilgihan, A. Okumuş, F. Nusair, K. Kwun, D. J. (2011). Information Technology Applications and Competitive Advantage İn Hotel Companies. Journal of Hospitality and Tourism Technology . 2(2):139-153.

Bird, D. (1990). Commonsense Direct Marketing. Lincolnwood: NTC business Books.

Blake, Kevin, (1996). "What's wrong with infomercials?", Consumers' Research Magazin., 79 (4).

Cappo, J., (2004). Reklamcılı̆ın Geleceği. (Çev. Fevzi Yalım). İstanbul: Mediacat Yayınları.

Dalgıç T. ve Leeuw M.(1994), Niche Marketing Revisited: Concept, Applications and Some European Cases. European Journal of Marketing, 28, 4, 39-55.

Dinç, B. (2018). Dijitalleşmenin Tüketici Alışkanlıklarına Etkisi. Ekonomistler Platformu, ekonomistler.org.tr

Dipasquale, Cara B., (2002). Direct Gets Respect, Advertising Age, 73 (25). Business Source Complete.

Dobkin, J (2007). Direct Marketing Strategies, Usa: The Danielle Adams Publishing Company. 
Durmaz, A. (1999a) Dijital Televizyonun Temelleri. Eskişehir: Anadolu Üniversitesi, Eğitim Sağlık ve Bilimsel Araştırma Çalışmaları Vakfı Yayını,

Edwards, J. 2001. The art of the infomercial. Brandweek, 42(32): 14-18.

Elden, M. (2005). Kurum Kimliği ve Kurumsal Reklam Arasındaki İlişki. Yeni Düşünceler, 1 (1) (https://dergipark.org.tr/tr/download/article-file/389076)

Elden, M., Ulukök, Ö. ve Yeygel, S. (2004). Şimdi Reklamlar... İstanbul: Sena Ofset.

Erdem, N. Structural Transformation of Advertising Narration in Turkey at Digital Era. 1st International Conference on New Trends in Communication. (http://acikerisim.ticaret.edu.tr/xmlui/handle/11467/1775? show=full)

Fiore, A. M., Lee, S. E., Kunz, G. ve Campbell, J. R. (2001). Relationships Between Optimum Stimulation Level And Willingness To Use Mass Customisation Options. Journal of Fashion Marketing and Management, 5(2), 99-107.

Fiore, A. M., Niehm, L., S. ve Lorenz, F. O. (2001). The Role of Experiential Value in Online Shopping. (www.emeraldinsight.com/10662243.htm)

Geller, L. K. (2002). Karlı Doğrudan Pazarlama. İstanbul: Sistem Yay.

Gray, E. (1995) Corporate image is a strategic concept. In Proceedings of the I3th Annual Conference of the Association of Management, Vancouver, 250-7.

Hatch, D. 1999. "Making DRTV work for you" Target Marketing, 22(9): 76-80.

Hope, W. ve Rosser, J. (2004). What is an Infomercial? Advertising \& Society Review. 5, (2). (https://muse.jhu.edu/article/169781)

Housden, M. ve Thomas, B. (2012) Direct Marketing Practice. Great Britain: ButterWorth Heinemann.

Kobs, Jim (2002). Profitable Direct Marketing. Lincolnwood: NTC Business.

Koch, J. (2008). Strategic Paths and Media Management. A Path Dependency Analysis of the German Newspaper Branch of High Quality Journalism, Schmalenbach Business Review 60(1):50-73.

Kotler, P., Kartajaya, H. ve Setiawan, I. (2017). Pazarlama 4.0. Gelenekselden Dijitale Geçiş. İstanbul: Optimist Kitap. 
Kotler P.(1989). From Mass Marketing to Mass Customization. Planning Review, September/October, 10-47

Kwon, H. J. ve Brinthaupt, T. M. (2015). The Motives, Characterist and Experinces of US Black Friday Shoppers. Journal of Global Fashion Marketing, 6/4, 292-302.

Larson, C. U. (2001). Persuasion. Belmort CA: Wadsworth

Leve, Richard J. (1999). Amplifying The Response To Direct Response Tv Advertising, Medical Marketing and Media. 34, 11; ABI/INFORM Collection

Lindstrom, M. (2006). Duyular ve Marka. İstanbul: Optimist Yay.

Longmore, P.K. (2016). Telethons Spectacle, Disability, and The Business of Charity, NewYork: Oxford University Press. (https://books. google.com.tr/books?id=h0L_CgAAQBAJ\&pg=PA9\&lpg=PA9\&$\mathrm{dq}=$ Jerry+Lewis+Telethon+informecial\&source=bl\&ots=btWMVOaTTV\&sig=ACfU3U1h67wc7q7o3r9Z262u_zJood0oqA\&hl=tr\&sa=X\&ved=2ahUKEwi9nu6_94DpAhULJBoKHWR-\#v=onepage\&q=Jerry\%20Lewis\%20Telethon\%20informecial\&f=false)

Moriarty, S. E. (1991). Creative Advertising: Theory and Practice. Englewood Cliffs, N.J. : Prentice-Hall

Nash, E. (2000). Direct Marketing, NY: McGraw-Hill

Özer Canarslan, N. (2017). Online Kitlesel Bireyselleştirmede Ürün Değeri ve Akış Deneyiminin Ödeme isteği ile Satın Alma Olasılı̆̆ına Etkisi. Anadolu Üniversitesi Sosyal Bilimler Enstitüsü Doktora Tezi.

Özdemir, K. (2012). İki Aşamalı Kümeleme Algoritması İle Pazar Bölümlemesi, Müşteri Profillerinin Belirlenmesi ve Niş Pazarların Tespiti. Uşak Üniversitesi Sosyal Bilimler Dergisi. 5 (3), 1-26.

Patterson, M., (1998). Direct Marketing in Post-Modernity: Neo-Tribes and Direct Communications. Marketing Intelligence\&Planning, $16 / 1$.

Peltier, J. W., Mueller, B., Rosen, R. G., (1992). Direct Response Versus Image Advertising, John Wiley \& Sons, Inc Journal Of Direct Marketing 6 (I) Winter

Pırnar Tavmergen, İ. (2002). Doğrudan Pazarlama Yönetimi. Ankara: Seçkin Yayınları

Piller, F. T. (2004). Mass Customization: Reflections on the State of the Concept. The International Journal of Flexible Manufacturing Systems, 16, 313-334. 
Pollay, R. W. (1983). Measuring the cultural values manifest in advertising. Current Issues and Research in Advertising, 6(1), 71-92.

Robins, K. İmaj. İstanbul:Ayrıntı Yayınları, 1999.

Roman, E. (1988). Telemarketing Campaigns That Work!, McGraw-Hill Inc.,US

Saucede, F., Codron, J-M. ve Fenneteau, H. (2014). Department Upkeep And Shrinkage Control: Two Key Variables İn Optimizing The Performance Of Fruit And Vegetables Departments, International Journal of Retail ve Distribution Management. 42(8):733-758

Simonson, I., \& Rosen, E. (2014). Absolute Value: What Really Influences Customers In The Age Of (Nearly) Perfect Information. New York, NY: Harper Business.

Solomon, M. R. (2004) Consumer Behavior: Buying, Having, and Being. Pearson Prentice Hall.

Kennedy, D. S. (2013). Direct Marketing. USA: Entepreneur Press

Martin, B. ve Bhimmy, A. C. (2002). Infomercials And Advertising Effectiveness: An Empirical Study. Journal of Consumer Marketing. 19 (6)

Mullin, R. (2002). Direct Marketing. Uk. Kogan Page

Odabaşı, Y. (2010). Küresel Kriz Ortamında Tüketici Davranışları, Tüketici Yazıları II, Hacettepe Üniversitesi, Tüketici-Pazar-Araştırma-Danışma-Test ve Eğitim Merkezi, TÜPADEM

http://www.tupadem.hacettepe.edu.tr/tuketici_yazilaril.pdf.

Odabaşı, Y. ve Oyman, M. (2002). Pazarlama İletişimi. Yönetimi İstanbul: MediaCat Yayınları

Okay, A. (2003) Kurum Kimliği Ankara: Mediacat Yayınları

Okay, A. (2005). Kurumsal İletişim ve Kurum Kimliği. Kurumsal İletişim Yönetimi., Eskişehir: Anadolu Üniversitesi Açıöğretim Yayınları

Okat Özdem, Ö. (2013). Doğrudan Tepki Reklamcıllğı: Türkiyedeki Uygulamaların Tüketici Perspektifinden Değerlendirilmesine Yönelik Bir Araştırma. Yeni Düşünceler. 7, 175-190.

Okat Özdem, E. Ö.(2011). Doğrudan Tepki Reklamlarının Tüketicilerin Satın Alma Eğilimlerine Etkileri

https://acikerisim.ege.edu.tr/xmlui/handle/11454/5921

Özdemir, Ş., Torlak, Ö. ve Vatandaş, C. (2013). Aile Yaşam Döngüsü ve Tüketim Sosyal Politika Çalışmaları Dergisi 16 (16). 
Özdemir, A. ve Orçanlı, K. (2012). İki Aşamalı Kümeleme Algoritması ile Pazar Bölümlemesi, Müşteri Profillerinin Belirlenmesi ve Niş Pazarların Tespiti. Uşak Üniversitesi Sosyal Bilimler Dergisi (5). 3.

Özer N., (2011). E-Hizmet Kalitesinin, E-Müşteri Bağlılı̆̆ı Üzerindeki Etkisi: Anadolu Üniversitesi Öğretim Elemanları Üzerine Bir Araştırma. Yüksek Lisans Tezi. Eskişehir: Anadolu Üniversitesi

Roberts, M. L. ve Berger, P.D (1999). Direct Marketing Management. Prentice Hall Inc. NJ

Russel, T. J. ve Lane. W. R. (1993). Kleppner's Advertising Procedure. Twelfth Edition. New Jersey: Prentice Hall, Englewood Cliffs.

Saucede, F. Fenneteau, H. Codron, J-M. (2014). Department Upkeep And Shrinkage Control: Two Key Variables In Optimizing The Performance Of Fruit and Vegetables Departments. International Journal of Retail and Distribution Management. https://www.researchgate.net/publication/266079214.

Seguela, J. (1988) Anneme Reklamcı Olduğumu Söylemeyin. İstanbul: Afa Yayınları

Simonson, I., ve Rosen, E. (2015). Yeni Tüketici (Çev: Cumhur Özkaya), İstanbul: The Kitap.

Simpson, L., Taylor, L., O’Rourke, K., ve Shaw, K. (2011). An Analysis of Consumer Behavior on Black Friday. American International Journal of Contemporary Research.

Spiller, L, ve Baier, M. (2005). Contemporary Direct Marketing. Upper Saddle River, NJ: Prentice-Hall.

Solomon, M. (2004). Consumer Behavior. Buying, Having and Being, Pearson Education International, New Jersey: USA.

Stone, Bob, (1988), Successful Direct Marketing Methods, 3. Bask1, Lincolnwood: National Textbank Co.

Subaşı, Ö. ve Bayraktar, A. (2018), Infomercial (Tanıtıcı) Reklamların Satın Almayı Etkileyen Faktörler Açısından Değerlendirilmesi, TUJOM, (2018), 3(3):258-2279

Taş, H. Y., Demirdöğmez, M. ve Küçükoğlu, M. (2017). Geleceğimiz Olan Z Kuşağının Çalışma Hayatına Muhtemel Etkileri. OPUS Uluslararası Toplum Araştırmaları Dergisi, 7 (13), 1031-1048.

Thomas, A. D, Lewison M., ve Hauser, W. J. (2007). Direct Marketing in Action, USA: Praeger Publishers 
Toffler, A. (2008). Üçüncü Dalga. S Yeniçeri (Çev.). İstanbul: Koridor. Tek, Ö.B. (1999). Pazarlama İlkeleri Türkiye Uygulamaları, Global Yönetimsel Yaklaşım (8. Baskı), İstanbul: Beta Yayınevi.

Topuz Savaş, A. (2018). Political Correctness and Politically Correct People: South Park Cases.

(http://25qt511nswfi49iayd31ch80-wpengine.netdna-ssl.com/wp-content/uploads/papers/mediasia2018/MediAsia2018_43328.pdf)

Topçu, Y. (2019). Tüketicilerin Bölge Orijinli Sarımsak Tercih Profilleri ve Piyasa Payları: TRA1 Bölgesi Örneği. International Congress on Agriculture and Forestry Research. 8-10 April 2019. Marmaris.

Varinli, İ., Çatı, K. (2010). Güncel Pazarlama Yaklaşımından Seçmeler. Ankara: Detay Yayıncilık.

Xardel, D. (1996). Doğrudan Pazarlama. İstanbul: Yeni Yüzyıl Kitaplığ1

Wells, W., Burnett, J. ve Moriarty, S (1992). Advertising Principles and Practice. Second Edition. New Jersey: Prentice Hall, Englewood Cliffs,

Wunderman, L. (1997). Being Direct - Direct Marketing That Works. Holbrook: Adams Media Corporation.

Young, B. J. (1993) https://doi.org/10.1002/sce.3730770303

Young, A. (1993). A Practical Guide to Direct Marketing. Admap, Temmuz-Ağustos, 25-33.

http://www.kto.org.tr/d/file/kurumsal-kimlik.pdf (Erişim tarihi: 3 Mart 2020).

file://C:/Users/user1/Downloads/653.pdf tez (Erişim tarihi: 12 Mart 2020).

http://www.pazarlama.org.tr/uploads/files/upk16.pdf\#page=104(Erişim tarihi: 15 Kasım 2020).

http://www.odd.org.tr/web_2837_1/entitialfocus.aspx?primary_ id $=421 \& \operatorname{target}=$ categorial $1 \&$ type $=33 \&$ detail $=$ single $($ Erişim tarihi: 15 Kasim 2020).

https://www.academia.edu/35860060/eTicaretin_Gelece\%C4\%9Fi_Kitlesel_Bireyselle\%C5\%9Ftirmede_mi(Erişim tarihi: 12 Mart 2020).

https://www.bakergoodchild.co.uk/a-history-of-direct-marketing-upto-the-1970s/ (Erişim tarihi: 3 Mart 2020).

https://www.simonandschuster.com/books / Montgomery-Ward-Co-Catalogue-and-Buyers-Guide-(1895)/Montgomery-Ward-Co/9781629145969(Erişim tarihi: 12 Mart 2020). 
http://docs.neu.edu.tr/staff/ahmet.arnavut/internet\%20reklamc\%-

C4\%B11\%C4\%B1\%C4\%9F\%C4\%B1_4.pdf s. 8 (Erişim tarihi: 3 Mart 2020).

https://www.bbc.com/news/business-55142724, (Erişim tarihi: 12 Mart 2020).

https:/www.haberturk.com/son-dakika-haberler-242-yillik-ingiliz-devi-iflas-etti-2888228-ekonomi(Erişim tarihi: 15 Kasım 2020).

https://www.bbc.com/news/business-55142724(Erişim tarihi: 15 Kasım 2020).

https://www.brandingturkiye.com/dunyanin-en-degerli-500-marka-

si-2019-tam-liste/(Erişim tarihi: 3 Mart 2020).

https://www.marketingturkiye.com.tr/haberler/amazon-kurucu-

su-jeff-bezos-hayat-hikayesi/(Erişim tarihi: 15 Kasım 2020).

https://www.star.com.tr/yerel-haberler/turkiyede-dogrudan-pazarlama-

ya-ayrilan-pay-21-milyar-dolara-ulasacak-3676020/(Erişim tarihi: 15 Kasim 2020).

http://www.hurriyet.com.tr/ekonomi/100-bin-dolara-kurduk-10-yilda-yarim-asirlik-sirketleri-gecti-19977790(Erişim tarihi: 24 Temmuz 2020).

https://www.hepsiburada.com/bizden-haberler(Erişim tarihi: 15 Kasım 2020).

https://www.ntv.com.tr/ekonomi/yemeksepeti-satildi-589-milyon-do-

larlik-basari-oykusu,XoJyuVmSNEWx_FRpHm0gug(Erişim tarihi: 15 Kasim 2020).

https://www.aa.com.tr/tr/sirkethaberleri/hizmet/hepsiburadadan-efsane-cumada-410-milyon-tllik-ciro/647503(Erişim tarihi: 3 Mart 2020).

https://www.ntv.com.tr/ekonomi/efsane-cumada-internetten-kart-

li-odemeler-1-4-milyar-tl-ile-rekor-kirdi-efsane,eXHarxKf1E-

CW7wTSA9yrFA

http://www.dpodulleri.org/(Erişim tarihi: 11 Temmuz 2020).

https://kristalelma.org.tr/media/10998/kri-stal-elma-2019-yo-netme-

li-k.pdf(Erişim tarihi: 11 Temmuz 2020).

https://www.altinorumcek.com/Altin-Orumcek/Tarihce/

https://www.effieturkiye.org/a/wp-content/uploads/2020/02/EF-

FIE-Turkiye-2020-Kategoriler.pdf(Erişim tarihi: 11 Temmuz 2020). 
https://www.eticaret.gov.tr/\#(Erişim tarihi: 3 Mart 2020). https://www.eticaret.gov.tr/Danisman(Erişim tarihi: 24 Temmuz 2020). https://www.sigortam.net/(Erişim tarihi: 3 Mart 2020). https://www.vakifbank.com.tr/(Erişim tarihi: 12 Mart 2020). https://www.evimitasarla.net/(Erişim tarihi: 3 Mart 2020). https://www.booking.com(Erişim tarihi: 12 Mart 2020). https://www.avis.com.tr/(Erişim tarihi: 12 Mart 2020). https://www.turkishairlines.com/(Erişim tarihi: 12 Mart 2020). https://www.biletix.com/anasayfa/TURKIYE/tr(Erişim tarihi: 12 Mart 2020).

https://partner.trendyol.com/onboarding/satici-formu(Erişim tarihi: 3 Mart 2020).

https:/tvdereklam.com/tr/m10/51/bant-reklam-nedir-(Erişim tarihi: 12 Mart 2020).

https://www.cedayart.com/tv/bant-reklam/10(Erişim tarihi: 12 Mart 2020).

https://tvdereklam.com/tr/m10/59/tv-reklami-vermek-isteyen-e-ticaret-firmalari-icin-oneriler(Erişim tarihi: 12 Mart 2020).

https://reklamajansi.com.tr/alt-bant-reklam-olcusu/(Erişim tarihi: 11 Temmuz 2020).

https://www.youtube.com/watch?v=wfh3Xv_Uid8(Erişim tarihi: 03 Ağustos 2020).

https://tvdereklam.com/tr/m10/53/advertorial-tanitici-reklam-nedirhttps://www.thebrandage.com/markalar-dijital-dunyayi-aplikasyonlarla-fethediyor(Erişim tarihi: 03 Ağustos 2020).

https://www.youtube.com/watch?v=yplP7E4Xfbs(Erişim tarihi: 24 Temmuz 2020).

https://www.youtube.com/watch?v=FVPK3m14tOs(Erişim tarihi: 24 Temmuz 2020).

https://tvdereklam.com/tr/m10/59/tv-reklami-vermek-isteyen-e-ticaret-firmalari-icin-oneriler(Erişim tarihi: 03 Ağustos 2020).

https://www.youtube.com/watch?v=Br2KSsaTzUc (Erişim tarihi: 3 Mart 2020).

https:/healthcaresuccess.com/blog/healthcare-marketing/why-davidogilvy-is-the-father-of-advertising-we-sell-or-else.html(Erişim tarihi: 03 Ağustos 2020). 
https://www.youtube.com/watch?v=DrLw0B4efz8(Erişim tarihi: 03 Ağustos 2020).

http://www.aljazeera.com.tr/makale/bal-reklamlari-kaldirilacak(Erişim tarihi: 11 Temmuz 2020).

https://www.kocaelibarisgazetesi.com/guncel/bir-degil-iki-degil-uc-degil-tam-12-bin-500-adet-h99648.html

https://www.sikayetvar.com/bal-deresi(Erişim tarihi: 11 Temmuz 2020). https://www.dideo.ir/v/yt/aA96LsHEdjQ/dshopping-max-extra-boya-tabancasi?list=PLw7gbKotVQEsapgREadLk6OzzUdpQmuKh(Erişim tarihi: 03 Ağustos 2020).

https://www.youtube.com/watch?v=-g5d02b4RcE(Erişim tarihi: 03 Ağustos 2020).

https://www.youtube.com/watch?v=YuZCrMz6xT0(Erişim tarihi: 03 Ağustos 2020).

https://www.inc.com/magazine/201604/kate-rockwood/infomercial-marketing-tips.html (Erişim tarihi: 3 Mart 2020).

https://www.youtube.com/watch?v=Rp40O9DudN4(Erişim tarihi: 3 Mart 2020).

https://www.youtube.com/watch?v=2GHzXrofZ3U

https://www.tsc.ca/(Erişim tarihi: 11 Temmuz 2020).

https://www.tsc.ca/pages/watchuslive(Erişim tarihi: 3 Mart 2020).

http://www.designersinc.ca/pdfs/The_Handbook_Direct_Marketing. pdf. (Erişim tarihi: 03 Ağustos 2020).

https://www.heraldextra.com/entertainment/television/as-jerry-lewisand-his-telethon-age-antics-and-drama/article_c998f450-b77b5b58-9bf1-e2b221287b35.html(Erişim tarihi: 03 Ağustos 2020).

http://www.tubisad.org.tr/tr/images/pdf/deloitte-turkey_tr_tmt_sayisal\%20tv\%20yayincilik_200911.pdf(Erişim tarihi: 12 Mart 2020). https://yeni.bmwonline.com.tr/seriler(Erişim tarihi: 11 Temmuz 2020). https://www.lordtshirt.com/sizden-gelenler(Erişim tarihi: 3 Mart 2020). https://www.icisleri.gov.tr/65-yas-ve-ustu-ile-kronik-rahatsizligi-olanlara-sokaga-cikma-yasagi-ek-genelgesi(Erişim tarihi: 03 Ağustos 2020).

https://mediacat.com/soz-cmoda-yuce-zerey/(Erişim tarihi: 7 Aralık 2020).

https://www.hurriyet.com.tr/ekonomi/artan-siparise-yeni-istihdam-41476113 
Researchgate.net/profile/Richard_Hollinger2/publication/267683436_2002_National_Retail_Security_Survey_Final_Report/links/54d2827c0cf25017917e5d65.pdf(Erişim tarihi: 03 Ağustos 2020).

https://www.hurriyet.com.tr/teknoloji/koronavirus-ile-birlikte-turkiyede-e-ticaret-satislari-artti-41473558(Erişim tarihi: 03 Ağustos 2020).

https://webrazzi.com/2020/03/19/corona-virus-salgini-ile-perakende-sektoru-magazalari-kapatip-e-ticarete-dondu/(Erişim tarihi: 03 Ağustos 2020).

https://www.haberturk.com/koronavirus-nedeniyle-turkiye-deki-teknoloji-magazalari-kapaniyor-haberler-2620990-teknoloji(Erişim tarihi: 03 Ağustos 2020).

https://worldef.net/blog/e-ticaret-ve-e-ihracat-dunyanin-gundeminde/ (Erişim tarihi: 03 Ağustos 2020).

https://webrazzi.com/2020/03/19/corona-virus-salgini-ile-perakende-sektoru-magazalari-kapatip-e-ticarete-dondu/.(Erişim tarihi: 15 Kasim 2020).

https://www.haberturk.com/koronavirus-nedeniyle-turkiye-deki-teknoloji-magazalari-kapaniyor-haberler-2620990-teknoloji(Erişim tarihi: 15 Kasım 2020).

https://www.portakalbahcem.com/tr/neden-finike-portakali(Erişim tarihi: 03 Ağustos 2020).

https://seferipazar.com/urun-kategori/koy-pazari-urunleri/ot/(Erişim tarihi: 03 Ağustos 2020).

https://www.karspeynircilik.com/kategoriler/kars-peyniri/?gclid=EAIaIQobChMI4b60luOe5wIVisqyCh0BJQZ3EAAYAiAAEgKbwfD_BwE(Erişim tarihi: 15 Kasım 2020).

https://www.kocakbaklava.com.tr/k/baklava-cesitleri/(Erişim tarihi: 03 Ağustos 2020).

https://www.basyazici.com.tr/pastirmalar?gclid=EAIaIQobChMIvqPKheae5wIVxYGyCh0muAJmEAAYAiAAEgLh4_D_BwE(Erişim tarihi: 15 Kasım 2020).

https://www.ofsut.com/(Erişim tarihi: 3 Mart 2020).

http://www.akinluletasi.com/product/productList?group=pipolar(Erişim tarihi: 11 Temmuz 2020). 
https://www.telkarisarayi.com/midyat-telkari-sarayi,TA-2650.html(Erişim tarihi: 03 Ağustos 2020).

https://www.nusrettaki.com/arama?q=oltu+ta\%C5\%9F\%C4\%B1\&category=

https://nesatilir.com/e-ticarette-yeni-nesil-kullanicilar/, (Erişim tarihi:

11 Temmuz 2020).

https://www.gozlemgazetesi.com/HaberDetay/21/1121396/e-ticaret-

te-z-kusagi-ruzgari-esiyor.html(Erişim tarihi: 3 Mart 2020).

https://www.brandingturkiye.com/nis-pazarlamaya-giris-nis-pazarlama-nedir/

https://www.iriadam.com/(Erişim tarihi: 3 Mart 2020).

https://www.rmgbuyukbeden.com/buyuk-beden-elbise(Erişim tarihi:

11 Temmuz 2020).

https://www.metalgiyim.com/(Erişim tarihi: 15 Kasım 2020).

https://www.vegandunyasi.com/(Erişim tarihi: 15 Kasım 2020).

https://www.decathlon.com.tr/C-529494-avcilik(Erişim tarihi: 15 Kasım 2020).

http://www.internetarsivi.metu.edu.tr/tarihce.php(Erişim tarihi: 7 Aralik 2020).

http://eticaretcagi.com/wp-content/uploads/2018/01/black-friday-2017-eticaret-cagi.pdf(Erişim tarihi: 7 Aralık 2020).

https://www.haberturk.com/turkiye-black-friday-de-kartlarla-34-milyar-tl-harcadi-2239120-teknoloji(Erişim tarihi: 7 Aralık 2020).

https://tr.sputniknews.com/ekonomi/201912031040748477-kara-cumada-kartli-odeme-rekoru-kirildi-47-milyar-tl/(Erişim tarihi: 7 Aralik 2020).

https://www.cnnturk.com/turkiye/diyanetin-cuma-hutbesinde-kara-cuma-tepkisi(Erişim tarihi: 11 Temmuz 2020).

https://webrazzi.com/2020/10/14/aylik-200-milyonun-uzerinde-ziyaretciye-sahip-hepsiburada-dan-cem-yilmaz-li-reklamlar/\#: :text $=$ Cem\%20Y\%C4\%B1lmaz'\%C4\%B1n\%20sevilen\%20karakterleri\%20Hepsiburada\&text=Hepsiburada'n $\%$ C4\%B1n\%2C\%20 Cem\%20Y\%C4\%B1lmaz\%20ve,7\%20reklam\%20filmi\%20\%C3\%A7ekti\%C4\%9Fini\%20belirtelim. (Erişim tarihi: 7 Aralık 2020).

https://www.tv100.com/cem-yilmaz-hepsiburada-ile-10-milyon-liralik-reklam-anlasmasi-yapti-tolga-cevik-n11-markasinin-yuzu-oldu-haber-520531(Erişim tarihi: 15 Kasım 2020). 
https://mediacat.com/hepsiburadanin-yeni-reklam-yuzu-cem-yilmaz/ (Erișim

tarihi: 15 Kasim 2020).

https://www.aa.com.tr/tr/sirkethaberleri/hizmet/hepsiburadanin-ye-

ni-reklam-yuzu-cem-yilmaz-oldu-/660072(Erişim tarihi: 15 Kasım 2020).

https://www.hepsiburada.com/samsung-galaxy-m31-2020-128-gb-sam-

sung-turkiye-garantili-p-hbv00000rtwp7(Erişim tarihi: 15 Kasım 2020).

https://mediacat.com/trendyoldan-super-super-acilis/(Erişim tarihi: 15

Kasim 2020).

https://mediacat.com/indirim-sov-basliyor-n11-com-tolga-cevik-rekla-

mi/(Erişim tarihi: 15 Kasım 2020).

https://www.thebrandage.com/e-ticaretin-gelecegini-degistirecek-tek-

nolojik-gelismeler-neler-8351(Erişim tarihi: 15 Kasım 2020).

https://pazarlamasyon.com/e-ticaretin-gelecegine-damga-vura-

cak-7-teknoloji-ve-strateji/(Erişim tarihi: 15 Kasım 2020).

https://www.technolat.com/ups-kargo-drone-tasimaciligina-hazirlani-

yor-8148/(Erişim tarihi: 15 Kasım 2020).

https://pazarlamasyon.com/e-ticaretin-gelecegine-damga-vura-

cak-7-teknoloji-ve-strateji/(Erişim tarihi: 15 Kasım 2020).

https://itrade.gov.il/turkey/mysize-penti-ile-anlasma-imzaliyor/(Erişim tarihi: 15 Kasım 2020).

https://www.xtrlarge.com/2020/04/16/mysizeid-akilli-telefon-kiyafet-beden-olcum/(Erişim tarihi: 15 Kasım 2020).

https://mysizeid.com/mysizeid-app/

https://pazarlamasyon.com/e-ticaretin-gelecegine-damga-vura-

cak-7-teknoloji-ve-strateji/(Erişim tarihi: 15 Kasım 2020).

https://www.dunya.com/sirketler/tek-tusla-deterjan-siparisi-veren-ca-

masir-makinesi-haberi-397063(Erişim tarihi: 15 Kasım 2020).

https://www.vestel.com.tr/vestelpandgsiparis(Erişim tarihi: 15 Kasım 2020).

https://technotoday.com.tr/samsung-family-hub-akilli-buzdolabi/(Erişim tarihi: 15 Kasım 2020). 